\title{
The Influence of Control Design on Energetic Cost during FES Induced Sit-to-Stand
}

\author{
Rasha Massoud \\ Department of Biomedical Engineering, Faculty of Mechanical and Electrical Engineering, Damascus University, \\ Damascus, Syria \\ Email: rqies@yahoo.com
}

Received 29 September 2014; revised 16 November 2014; accepted 2 December2014

Copyright (C) 2014 by author and Scientific Research Publishing Inc.

This work is licensed under the Creative Commons Attribution International License (CC BY). http://creativecommons.org/licenses/by/4.0/

(c) (i) Open Access

\section{Abstract}

This paper highlights the benefits of using intelligent model based controllers to produce FES induced sit-to-stand movement (FES-STS), in terms of reducing energy cost and producing more natural responses in comparison with conventional controllers. A muscle energy expenditure model for the quadriceps is implemented in the control design of FES-STS, then simulation is run for three different control designs: an adaptive neuro-fuzzy inference system controller (ANFIS), a conventional PID controller, and a hybrid ANFIS-PID controller. The PID control strategy results in negative energy expenditure of the quadriceps at the end of the STS initiation phase, this negative energy is caused by the high lengthening speeds at the muscle fiber level, which may lead to muscle fatigue or damage. Contrary to PID controller, model based controllers show positive energy expenditure, lower energy costs, and more natural curves of energy expenditure and knee torques.

\section{Keywords}

Adaptive Neuro-Fuzzy Inference System (ANFIS), Functional Electrical Stimulation (FES), Sit to Stand (STS), Energitics, Musculoskeletal Modeling, Simulation

\section{Introduction}

Standing up from a chair is one of the most important functional tasks that spinal cord injury (SCI) people really need to improve their daily life, they can perform this task with the help of a technique known as functional electrical stimulation (FES). In FES, an electrical stimulation signal is applied to the paralyzed muscle to compensate for lost signals from the disconnected central nervous system, and to perform functional movements [1].

FES with surface electrodes is easy to apply by patients [2] [3], it has light weight, it does not depend on the 
shape and the size of the leg as some orthotics do, it activates muscles and helps producing metabolic energy, and it has many beneficial effects on SCI subjects' health [4] [5].

Studies have suggested that all SCI subjects with a lesion lower than T-12 and their lower limb muscles are in a good condition, are able to stand up by using their upper body efforts accompanied by FES application on their quadriceps muscles [6]. This standing up method produces high torques at the knee joint which may cause damage to the muscle tissue and joint ligaments. To overcome this problem, a proper control strategy can be designed to give the best suitable stimulation parameters for less damage and higher efficiency [6].

Since 1960s, many studies have been conducted on designing control methods to achieve FES sit-to-stand (STS) transfer [7]; these control methods range from simplest on-off controllers [7]-[13] to more complex designs such as model based controllers [14]-[17] and other different types of controllers [18]-[20]. Hussain et al. have developed different control strategies to obtain FES induced sit-to-stand movement (FES-STS): (ANFISonly, ANFIS-PID, and PID-only), they compared and evaluated the three controllers in terms of error reduction in the knee joint angle, and knee moments [21].

It has been proved that most FES induced exercises resulted in low power output to expended metabolic energy ratio (efficiency) compared with normal people [22]-[25]. For this reason, energetic analysis should be taken into account when studying FES induced movement. Energy analysis aims to optimize metabolic energy to activate the cardiovascular system and obtain the corresponding mechanical power output, and to maintain high efficiency and prolong the exercise period before the occurrence of muscle fatigue at the same time [26].

Researchers have been keen on studying the influence of FES system design on energy consumption and power output [27] [28]. And some have proved the impact of FES control strategies on the performance of FES exercise systems in terms of maintaining constant power output, improving efficiency, consistency, reliability, and prolonging the duration of FES exercise [26] [29]-[31].

This study aims to evaluate the three controllers which were used in [21] depending on the hypothesis of minimum metabolic cost which guarantees high efficiency and more natural movement patterns [32]. Moreover, the main target of this study is to find whether intelligent model based controllers have better performance than conventional ones, in terms of minimizing metabolic energy consumption and damage prevention during FESSTS.

\section{Methods}

Since this work is a simulation study, the most important issue to take into account is the accuracy of the models involved in the simulation. Following is the description of these models:

\subsection{Humanoid Model}

The humanoid model is developed using Visual Nastran software, which is a powerful CAD tool used for 3-D modeling [33]. The model is $1.80 \mathrm{~m}$ high and it weighs $75.35 \mathrm{Kg}$, more description about the humanoid model parameters can be found in detail in [21].

Although the model was built in 3D as illustrated in Figure 1, humanoid movement is studied in the sagital plane, since only the quadriceps muscle group (knee extensors) is stimulated.

\subsection{Human Muscle Model}

Muscle models can be classified into two major types:

1) Black box models: This type reproduces input-output behavior of the real muscle depending on the experimental results, it leads to fast computations which make it executable and practically applicable. However, its structure does not reflect muscle physiology [34] [35].

2) Physiological models: This type is the most commonly used in movement control studies [14] [36], since it describes the observed behavior of the muscle components, starting from excitation to the force production. Its relations are also relatively simple and describe familiar concepts that have been well verified [37]. Models of this type mostly use the elements of Hill muscle model [38].

A comparison between the two types is illustrated in Table 1. Black box models are often used to build motion control strategies, while physiological models are used for both motion control and analysis (power and efficiency). 


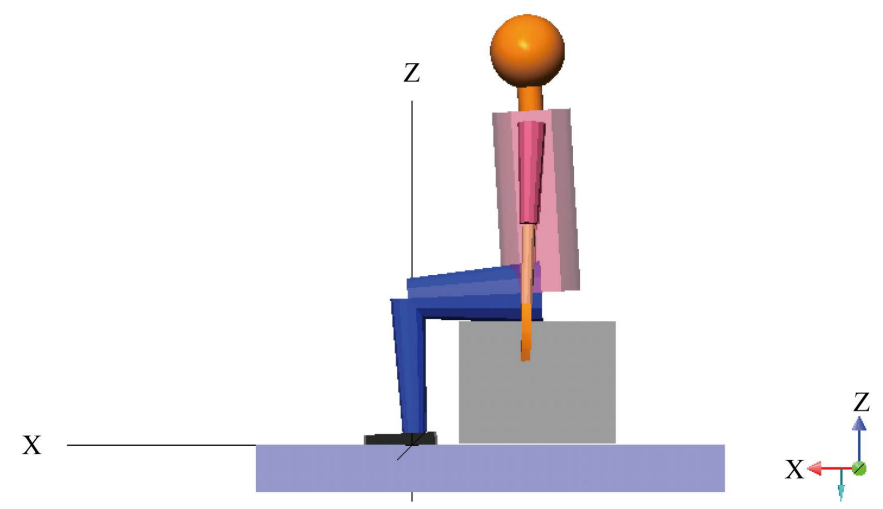

Figure 1. The humanoid sits on a chair at the beginning of the initiation phase of STS.

Table 1. A comparison between the two main muscle model types.

\begin{tabular}{|c|c|c|}
\hline \multirow{2}{*}{ Muscle model properties } & \multicolumn{2}{|l|}{ Muscle model type } \\
\hline & Black box [34] [35] & Physiological model [14] [36] \\
\hline Model input & Muscle activation & $\begin{array}{l}\text { At least three inputs, such as: activation intensity, activation } \\
\text { frequency, joint angle, joint angular velocity, and } \\
\text { musculotendon path length. }\end{array}$ \\
\hline Model output & $\begin{array}{l}\text { Muscle moment applied to the } \\
\text { corresponding joint }\end{array}$ & Muscle force, length, velocity, and moment arm. \\
\hline Basic principle & $\begin{array}{l}\text { Using experimental input-output data to } \\
\text { identify the model }\end{array}$ & $\begin{array}{l}\text { Based on physiological experimental observations of the } \\
\text { muscle, such as force-length and force-velocity relations. }\end{array}$ \\
\hline Model parameters & Few & Large number \\
\hline Parameter adjustment & Adjusted for each subject & Adjusted for each subject \\
\hline Simplicity & $\begin{array}{l}\text { Depending on the complexity of the used } \\
\text { modeling method }\end{array}$ & Complex, but it is available as a software with GUI [36]. \\
\hline Training data sets & Essential & None \\
\hline Muscle physiological behavior & Does not take it into account. & It gives a clear idea about intramuscular behavior. \\
\hline $\begin{array}{l}\text { Used to calculate muscle } \\
\text { energy expenditure }\end{array}$ & No & Yes \\
\hline
\end{tabular}

In this study, quadriceps muscles group (which consists of four muscles: Rectus femoris, Vastus medialis, Vastus medium, and Vastus lateralis) is modeled in Virtual Muscle 4.0.1 software. Virtual muscle builds realistic physiological muscle models in Matlab/Simulink [36]. All muscle models used in this study have three inputs: activation signal, musculotendon path length, and stimulus frequency for FES recruitment, while the outputs are muscle force, length, and velocity. Both muscle length and velocity are normalized by the optimal resting length of the muscle $\left(\mathrm{L}_{\mathrm{CE}(\mathrm{OPT})}\right)$. Parameters of the muscle model are obtained from [39].

\subsection{Muscle Energy Expenditure Model}

In this study, an activation signal with a frequency of $20 \mathrm{~Hz}$ is used to stimulate the muscles. At this low frequency, muscle fatigue is influenced by the temporal levels of intra and extra cellular metabolites and electrolytes [40]. Muscle fatigue is associated with the decreased levels of adenosine triphosphate (ATP), low cellular $\mathrm{PH}$ and the increased inorganic phosphate, leading to the reduction in muscle energy [41]. Moreover, muscle energy is produced through chemical reactions leading to breaking ATP into adenosine diphosphate. Each time ATP molecule breaks down through the enzyme ATPase, the energy released is used for binding actin and myosin molecules at the cross bridge and subsequent unbinding. The macroscopic output is the shortening or the lengthening tension of the muscle [41]. There are two biochemical pathways for production of adenosine triphosphate (ATP), an aerobic pathway where $\mathrm{O}_{2}$ flow from the blood to the mitochondrion is important to generate the aerobic energy, and anaerobic pathway at the sites of inadequate $\mathrm{O}_{2}$ flow to mitochondria. 
This study uses "a phenomenological model of skeletal muscle energy expenditure developed for use with Hill-type muscle model" by Umberger, et al., "this model predicts human muscle energy expenditure over the full activation range, and it is based almost entirely on mammalian muscle data, with preference given to human data where possible" [42].

The total rate of muscle energy expenditure $(\dot{E})$ expressed in $\left(\mathrm{W} \cdot \mathrm{Kg}^{-1}\right)$ can be represented by Equation (1) [42]:

$$
\dot{E}=\dot{h}_{A}+\dot{h}_{M}+\dot{h}_{S L}+\dot{w}_{C E}
$$

where $\dot{h}_{A}$ is the activation heat rate, $\dot{h}_{M}$ is the maintenance heat rate, $\dot{h}_{S L}$ is the shortening/lengthening heat rate and $\dot{w}_{C E}$ is the mechanical work rate. The whole model equations can be found in detail in [42].

This model is built for rectus femoris and the three vasti muscles by using Matlab/Simulink, then it is integrated in the overall control design. In this study, this model is selected because it is easy to understand, its parameters are available or can be obtained easily from literature. It is also well studied and evaluated by experimental results [43].

\subsection{Control Set-Up}

Three control scenarios are applied to control FES induced sit-to-stand, muscle energy expenditure is calculated, and the controlled motion is studied and evaluated for each scenario.

A closed loop PID controller is implemented in the first control method, while the second method uses an open loop ANFIS controller based on inverse modeling. Subsequently, the last scenario is attained by using a closed loop ANFIS-PID controller. The three control strategies are described thoroughly in [21] and are illustrated in Figure 2.

Both PID and ANFIS-PID controllers depend on the closed loop method, where the error signal between reference and actual knee trajectories is fed to the controller which, in turn, sends an activation signal to the muscle

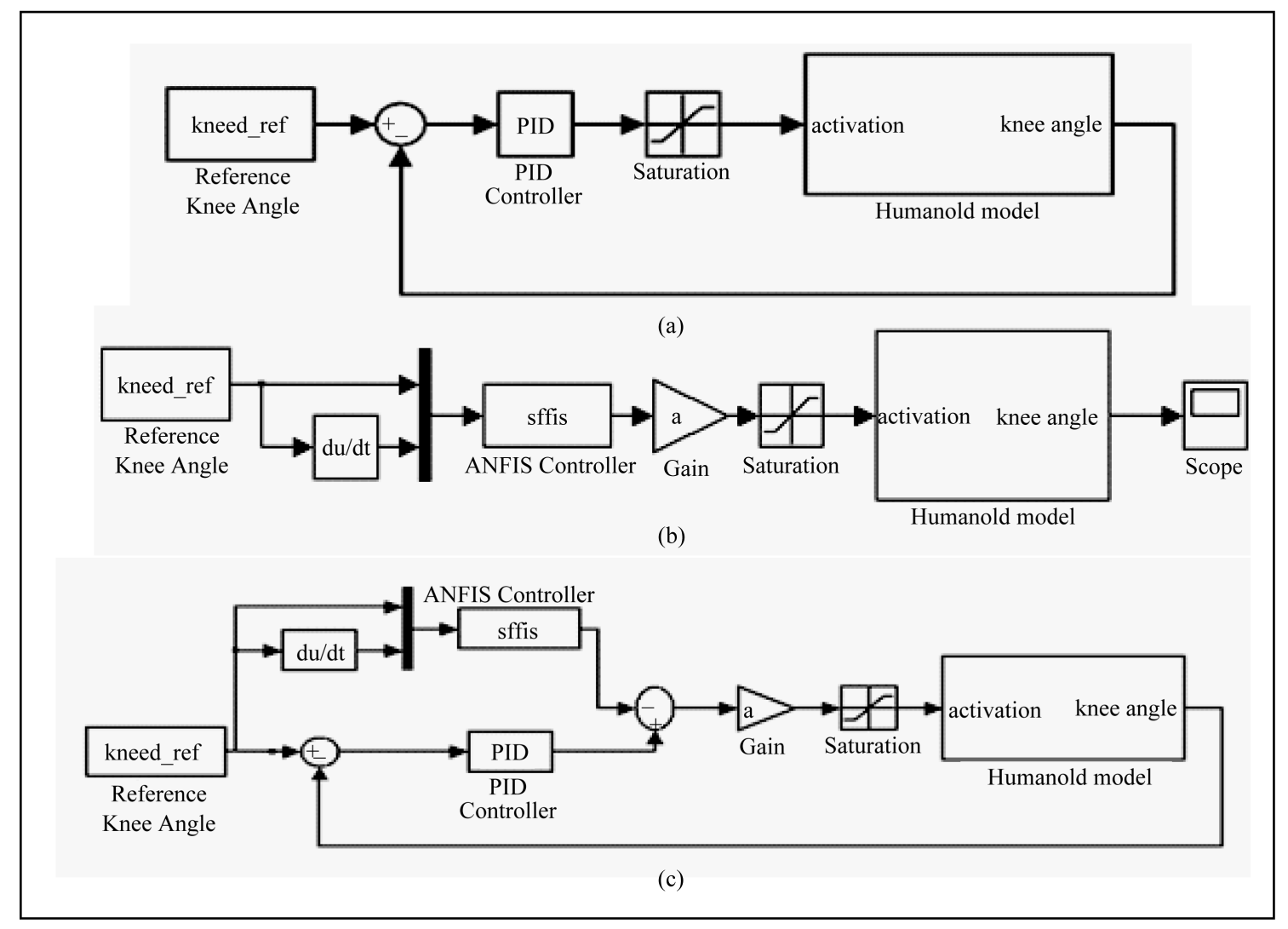

Figure 2. The three control designs: (a) PID-only; (b) ANFIS-only; (c) ANFIS-PID. 
model to produce a force converted to an active torque applied to the knee joint causing the desired FES-STS motion. The ANFIS-only controller uses an open loop method, where both reference angle of the knee joint and its derivative (angular velocity) are the inputs of the controller, while the controller's output follows the same path that the two other controllers' outputs follow.

\section{Results}

Energy expenditure model is integrated into the humanoid model, and simulation of FES-STS is run for the three control strategies explained above: (ANFIS-only, ANFIS-PI, and PID-only). Figure 3 shows the torque produced by the quadriceps for each control method, it is obvious that the average torque values are the lowest when ANFIS-only control method is used, nevertheless knee extension torque increases during the rising phase and reaches its peak value shortly after seat off.

On the other hand, total knee torques produced by ANFIS and ANFIS-PID control strategies starts earlier, and are more spontaneous than those produced by PID-only, thus the full standing steady state also occurs earlier as shown in Figure 3.

The average energy expenditure at the muscle level during FES-STS varies for the different control strategies, Table 2 demonstrates the energy rate values for the quadriceps for the two parts of the motion: transition from sit to stand and maintaining the upright position. The minimum mean overall energy rate occurs when ANFISonly controller is used, while using PID-only controller resulted in a minimum mean STS transfer energy rate, this is due to the negative energy values observed on its energy curve as illustrated in Figure 4. Both ANFIS and ANFIS-PID control strategies result in positive muscle energy expenditure, while PID-only control method is resulted in negative energy values at some stages (see Figure 4).

The mean energy cost values (see Table 2) are larger than the experimental values reported in [27] which are (246.87 W and 220.84 W). Even though they used quadriceps stimulation to maintain standing, they used a significant amount of support on the hands, contrary to this study which uses unsupported standing. The higher energy values in this study can be explained by the differences in volumes and histological structures between upper and lower limbs. [27] indicated that lower limb muscles, specifically the quadriceps consist mainly of red, oxidative slow-twitch fibers, while the upper limb muscles consist of white, glycolytic fast-twitch fibers. Accordingly,

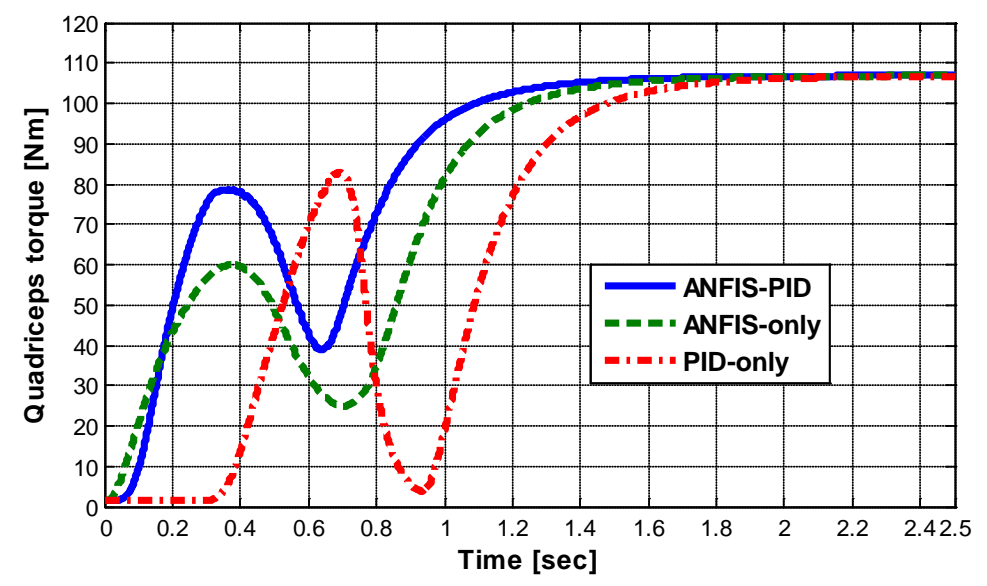

Figure 3. Quadriceps torque applied to the knee joint.

Table 2. Energy rate of the quadriceps during FES-STS movement (STS transfer + standing), the values are expressed in mean \pm STD.

\begin{tabular}{lcc}
\hline Energy [W] Mean \pm STD & PID-only & ANFIS-only \\
\hline $\begin{array}{l}\text { Energy (sit to stand transfer) } \\
\text { Energy (maintaining upright position) }\end{array}$ & $213.63 \pm 158.09$ & $235.89 \pm 86.86$ \\
$\begin{array}{l}\text { Energy (The overall period) sit to stand transfer } \\
+ \text { during standing }\end{array}$ & $309.53 \pm 5.33$ & $307.54 \pm 1.71$ \\
\hline
\end{tabular}




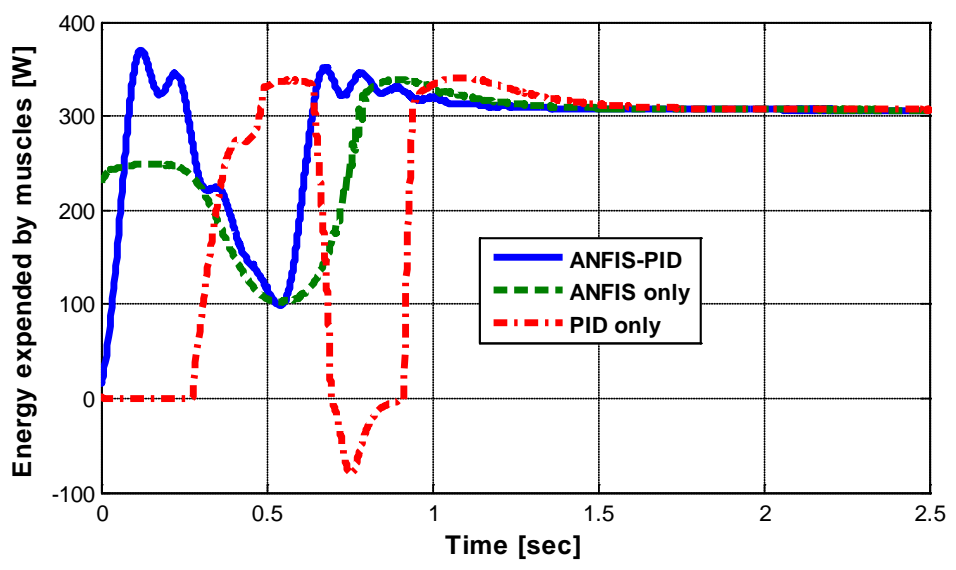

Figure 4. Energy expenditure of the quadriceps.

lower limb muscles consume more metabolic energy than upper limb ones.

\section{Discussion}

As illustrated in Figure 3, the total quadriceps torque starts for both ANFIS and ANFIS-PID control methods earlier than the PID-only control method. This is because of the ANFIS modeling assumptions, given that the ANFIS model was built by using a free swinging leg with a resting knee angle of $80^{\circ}$. At this knee angle, the inverse ANFIS model does not produce any muscle activation and thus no active torque is produced. However, in FES sit-to-stand movement, the knee angle starts at $90^{\circ}$ which corresponds to the production of muscle activation and consequently the growth of the knee torque at that position.

By using PID-only control strategy, the energy expenditure by the quadriceps becomes negative at some points of the STS period (as shown in Figure 4). This means that the work carried out by the contractile element of the muscle (CE) is greater than the heat produced at lengthening velocities, Figure 5 displays different energy rates released by rectus femoris during FES-STS controlled by PID-only controller, it is obvious that the mechanical work rate has negative values while the other two energy rates are always positive during the movement. This implies that some of the work done on the muscle during a stretch is stored. According to [42] and [44] it is found that series elastic element of the muscle (SEE) does not seem to be the major site of energy storage, and the contractile element (CE) may store energy too.

The initiation phase of FES-STS starts when hip flexion torques increase until they reach their peak, at this moment stretching in the quadriceps takes place, however the PID controller applies high stimulation intensities on the muscle causing increased recruitment of the muscle motor units. At this time no additional work is done and mechanical energy is stored to be used later in the rising phase where both knee and hip joints are extended. This explains why energy curves reach a minimum at the end of the initiation phase for the three control strategies.

Figure 6 indicates that the negative energy expenditure accompanied by using the PID-only control design is caused by high lengthening speeds at the muscle level rather than over-lengthening. This speed is four times the lengthening speed occurs by the ANFIS-only controller. This high speed may cause muscle fatigue or damage [45].

The resulted energy values are compared with the values cited in the literature. The resulted mean energy rate for rectus femoris only in this study is $151.06 \mathrm{~W} / \mathrm{Kg}$ which is within the range reported by [42], and it is in consistence with their simulation and experimental results. Moreover, similar results were obtained by [43], where exercise energy consumptions for the leg (simulation and practical) were close to the range of the mean energy rate values obtained in this study (see Table 2).

\section{Conclusions}

This research sheds light on the role of musculoskeletal modeling and simulation in understanding the relation between human movement and muscle energy expenditure. Through simulation, it is easy to access to that val- 


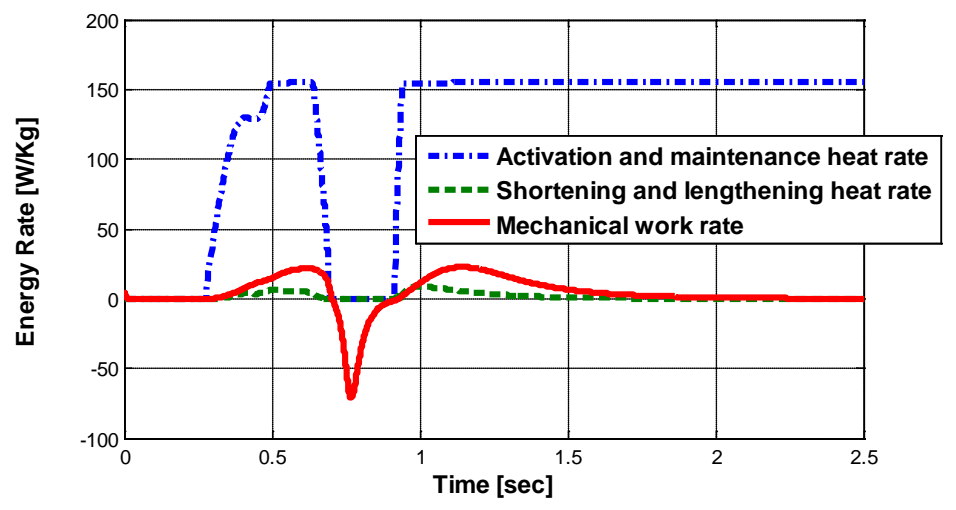

Figure 5. Different energy rates released from rectus femoris during FESSTS. The rectus femoris mass is $0.218 \mathrm{Kg}$.

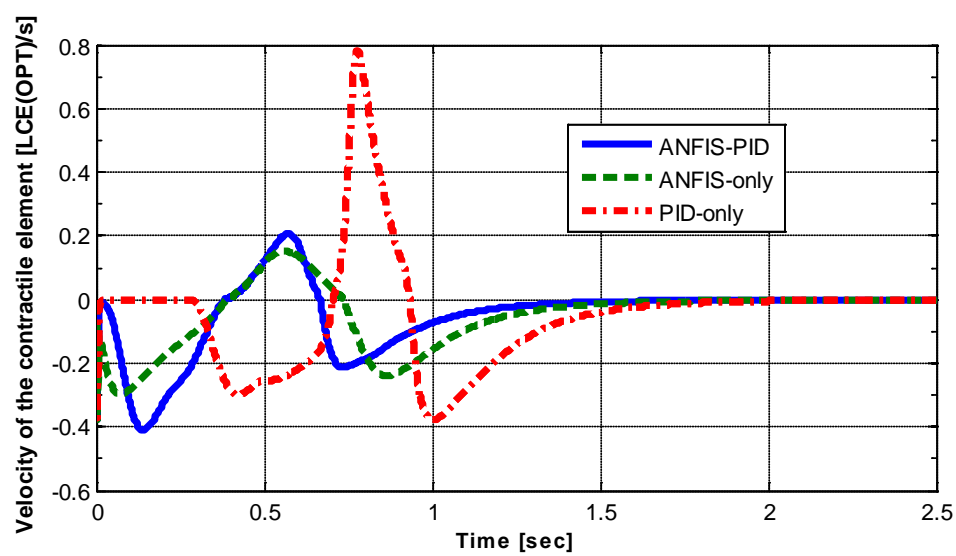

Figure 6. Velocity of the contractile element during FES-STS, positive velocities caused by muscle fiber lengthening, the velocity is normalized by the optimal resting length of the muscle $\left(\mathrm{L}_{\mathrm{CE}(\mathrm{OPT})}\right)$ so its unit is $\mathrm{LCE}(\mathrm{OPT}) \mathrm{s}^{-1}$.

ues which cannot be reached by experimental trials, such as the length and the speed of the contractile element, the activation torque produced by the muscle, or the different energy rates released in the muscle.

According to the simulation results, it is clear that ANFIS-only control for FES-STS has the best energetic performance, since its energy expenditure and knee torque curves are the smoothest, the most natural, and have the lowest peak values. However, experiments on human subjects are still needed to ensure these results.

The PID controller regulates stimulation intensities depending on the deference between reference and actual knee trajectories, the controller does not also take the actual state of the muscle or its activation level into account. This study suggests developing an ANFIS_PID controller to control FES_STS transfer. The controller depends on an adaptive neural network which adjusts its weights according to the inversed musculoskeletal model, and thus the whole control process will be improved.

In conclusion, control strategies which depend on inverse models of musculoskeletal systems produce more natural responses, and cause less damage to the muscle, regardless of the complexity of their design. Nevertheless, this outcome should be confirmed by experimental work.

\section{References}

[1] Hamid, S. and Hayek, R. (2008) Role of Electrical Stimulation for Rehabilitation and Regeneration after Spinal Cord Injury: An Overview. European Spine Journal, 17, 1256-1269. http://dx.doi.org/10.1007/s00586-008-0729-3

[2] Khattar, B., Banerjee, A., Reddi, R. and Dutta, A. (2012) Feasibility of Functional Electrical Stimulation-Assisted Neurorehabilitation following Stroke in India: A Case Series. Case Reports in Neurological Medicine, 2012, Article ID: 830873. http://dx.doi.org/10.1155/2012/830873 
[3] Peckham, P.H. and Knutson, J.S. (2005) Functional Electrical Stimulation for Neuromuscular Applications. Annual Review of Biomedical Engineering, 7, 327-360. http://dx.doi.org/10.1146/annurev.bioeng.6.040803.140103

[4] Perry, J. (1992) Gait Analysis: Normal and Pathological Function. SLACK Incorporated, Thorofare.

[5] Spadone, R., Merati, G., Bertocchi, E., Mevio, E., Veicsteinas, A., Pedotti, A. and Ferrarin, M. (2003) Energy Consumption of Locomotion with Orthosis versus Parastep-Assisted Gait: A Single Case Study. Spinal Cord, 41, 97-104. http://dx.doi.org/10.1038/sj.sc.3101420

[6] Horch, K. and Dhillon, G. (2004) Neuroprosthetics: Theory and Practice. World Scientific Publishing Co., Singapore City.

[7] Kantrowitz, A. (1960) Electronic Physiologie Aids: A Report of the Maimonides Hospital. Brooklyn, New York.

[8] Reswick, J. (1972) Development of Feedback Control Prosthetic and Orthotic Devices. Advances in Biomedical Engineering Academic Press, New York.

[9] Bajd, T., Kralj, A., Sega, J., Turk, R., Benko, H. and Strojnik, P. (1981) Use of a Two-Channel Functional Electrical Stimulator to Stand Paraplegic Patients. Physical Therapy, 61, 526-527.

[10] Ewins, D., Taylor, P., Crook, S., Lipnynski, R. and Swain, L. (1988) Practical Low Cost Stand/Sit System for Mid-Thoracic Paraplegics. Journal of Biomedical Engineering, 10, 184-188. http://dx.doi.org/10.1016/0141-5425(88)90098-2

[11] Jaeger, R., Yarkony, G. and Smith, R. (1989) Standing the Spinal Cord Injured Patient by Electrical Stimulation: Refinement of a Protocol for Clinical Use. IEEE Transaction on Biomedical Engineering, 36, 720-728. http://dx.doi.org/10.1109/10.32104

[12] Poboroniuc, M., Fuhr, T., Riener, R. and Donaldson, N. (2002) Closed-Loop Control for FES-Supported Standing-Up and Sitting-Down. Proceedings of 7th Annual Conference of the International Functional Electrical Stimulation Society, Ljubljana, 25-29 June 2002, 307-309.

[13] Donaldson, N. and Yu, C.H. (1998) A Strategy Used by Paraplegics to Stand up Using FES. IEEE Transactions on Rehabilitation Engineering, 6, 162-167. http://dx.doi.org/10.1109/86.681181

[14] Riener, R. and Fuhr, T. (1998) Patient-Driven Control of FES Supported Standing up: A Simulation Study. IEEE Transactions on Rehabilitation Engineering, 6, 113-124. http://dx.doi.org/10.1109/86.681177

[15] Riener, R., Ferrarin, M., Pavan, E.E. and Frigo, C.A. (2000) Patient-Driven Control of FES-Supported Standing up and Sitting down: Experimental Results. IEEE Transactions on Rehabilitation Engineering, 8, 523-523. http://dx.doi.org/10.1109/86.895956

[16] Abu Bakar, N. and Abdullah, A. (2011) Dynamic Simulation of Sit to Stand Exercise for Paraplegia. IEEE International Conference on Control System, Computing and Engineering, Penang, 25-27 November 2011, 114-118.

[17] Afzal, T., Khan, L. and Tokhi, M. (2010) Simulation of a Patient Driven Strategy for FES Supported Sit-to-Stand Movement. IEEE International Conference on Information and Emerging Technologies (ICIET), Karachi, 14-16 June 2010, $1-4$.

[18] Dolan, M., Andrews, B. and Veltink, P. (1998) Switching Curve Controller for FES-Assisted Standing up and Sitting down. IEEE Transactions on Rehabilitation Engineering, 6, 167-171. http://dx.doi.org/10.1109/86.681182

[19] Davoodi, R. and Andrews, B. (1998) Computer Simulation of FES Standing up in Paraplegia: A Self-Adaptive Fuzzy Controller with Reinforcement Learning. IEEE Transactions on Rehabilitation Engineering, 6, 151-161. http://dx.doi.org/10.1109/86.681180

[20] Donaldson, N. and Yu, C.H. (2000) Experiments with CHRELMS Patient-Driven Stimulator Controllers for the Restoration of Function to Paralysed Legs. Proceedings of Instrumentations Mechanical Engineers, 214, 1-20. http://dx.doi.org/10.1243/0954411001535200

[21] Hussain, R., Massoud, R. and Al-Mawaldi, M. (2014) ANFIS-PID Control FES-Supported Sit-to-Stand in Paraplegics: (Simulation Study). Journal of Biomedical Science and Engineering, 7, 208-217. http://dx.doi.org/10.4236/jbise.2014.74024

[22] Hunt, K.J., Ferrario, C., Grant, S., Stone, B., McLean, A.N., Fraser, M.H. and Allan, D.B. (2006) Comparison of Stimulation Patterns for FES-Cycling Using Measures of Oxygen Cost and Stimulation Cost. Medical Engineering and Physics, 28, 710-718. http://dx.doi.org/10.1016/j.medengphy.2005.10.006

[23] Glaser, R.M., Figoni, S.F., Hooker, S.P., et al. (1989) Efficiency of FNS Leg Cycle Ergometry. 11th Annual International Conference of the IEEE Engineering in Medicine \& Biology Society, 3, 961-963.

[24] Kjaer, M., Perko, G., Secher, N.H., et al. (1994) Cardiovascular and Ventilatory Responses to Electrically Induced Cycling with Complete Epidural Anaesthesia in Humans. Acta Physiologica Scandinavica, 151, 199-207. http://dx.doi.org/10.1111/j.1748-1716.1994.tb09738.x

[25] Popovic, D., Tomovic, R. and Schwirtlich, L. (1989) Hybrid Assistive System—The Motor Neuroprosthesis. IEEE 
Transactions on Biomedical Engineering, 36, 729-737. http://dx.doi.org/10.1109/10.32105

[26] Massoud, R. (2007) Intelligent Control Techniques for Spring Assisted FES-Cycling. Ph.D. Thesis, The University of Sheffield, Sheffield.

[27] Isakov, E., Mizrahi, J. and Najenson, T. (1986) Biomechanical and Physiological Evaluation of FES-Activated Paraplegic Patients. Journal of Rehabilitation Research and Development, 23, 9-19.

[28] Kangude, A., Burgstahler, B. and Durfee, W. (2010) Engineering Evaluation of the Energy-Storing Orthosis FES Gait System. Proceedings of the IEEE Engineering in Medicine and Biology Society, 5927-5930.

[29] Hunt, K.J., Stone, B., Negard, N.O., Schauer, T., Fraser, M.H., Cathcart, A.J., et al. (2004) Control Strategies for Integration of Electric Motor Assist and Functional Electrical Stimulation in Paraplegic Cycling: Utility for Exercise Testing and Mobile Cycling. IEEE Transactions on Neural Systems and Rehabilitation Engineering, 12, 89-101. http://dx.doi.org/10.1109/TNSRE.2003.819955

[30] Bellman, M.J., Cheng, T.H., Downey, R.J. and Dixon, W.E. (2014) Stationary Cycling Induced by Switched Functional Electrical Stimulation Control. American Control Conference (ACC), Portland, 4-6 June 2014, 4802-4809.

[31] Gollee, H., Hunt, K.J. and Wood, D.E. (2004) New Results in Feedback Control of Unsupported Standing in Paraplegia. IEEE Transactions on Neural Systems and Rehabilitation Engineering, 12, 73-80. http://dx.doi.org/10.1109/TNSRE.2003.822765

[32] Miller, R.H., Umberger, B.R., Hamill, J. and Caldwell, G.E. (2011) Evaluation of the Minimum Energy Hypothesis and Other Potential Optimality Criteria for Human Running. Proceedings of the Royal Society B, 279, 1498-1505.

[33] Wang, S.L. (2001) Motion Simulation with Working Model 2D and MSC.visualNastran 4D. Journal of Computer and Information Science and Engineering, 1, 193-196. http://dx.doi.org/10.1115/1.1389462

[34] Ferrarin, M., Palazzo, F., Riener, R. and Quintern, J. (2001) Model-Based Control of FES-Induced Single Joint Movements. IEEE Transactions on Neural Systems and Rehabilitation Engineering, 9, 245-257. http://dx.doi.org/10.1109/7333.948452

[35] Jailani, R., Tokhi, M., Gharooni, S. and Hussain, Z. (2009) A Novel Approach in Development of Dynamic Muscle Model for Paraplegic with Functional Electrical Stimulation. Journal of Engineering and Applied Sciences, 4, 272-276.

[36] Song, D., Cheng, E., Brown, I., Davoodi, R. and Loeb, G. (2008) Virtual Muscle 4.0.1: Muscle Model for Matlab User’s Manual. Alfred Mann Institute, Los Angeles.

[37] Hill, A.V. (1938) The Heat of Shortening and the Dynamic Constants of Muscle. Proceedings of the Royal Society of London, 126, 136-195. http://dx.doi.org/10.1098/rspb.1938.0050

[38] Fung, Y.C. (1981) Biomechanics, Mechanical Properties of Living Tissues. Springer-Verlag, New York.

[39] Rustin, C. (2010) Physiological Modelling and Dynamic Simulation of Human Walking. Ph.D. Thesis, Faculty Polytechnique de Mons, Mons University, Mons.

[40] Levin, O. and Mizrahi, J. (1999) EMG and Metabolite-Based Prediction of Force in Paralyzed Quadriceps Muscle under Interrupted Stimulation. IEEE Transactions on Rehabilitation Engineering, 7, 301-314. http://dx.doi.org/10.1109/86.788467

[41] Wasserman, K., Hansen, J.E., Sue, D.Y., Stringer, W. and Whipp, B. (2005) Principles of Exercise Testing and Interpretation. Lippincott Williams \& Wilkins, Philadelphia.

[42] Umberger, B.R., Gerritsen, K.G.M. and Martin, P.E. (2003) A Model of Human Muscle Energy Expenditure. Computer Methods in Biomechanics and Biomedical Engineering, 6, 99-111. http://dx.doi.org/10.1080/1025584031000091678

[43] Bisi, M.C. and Stagni, R. (2010) A Modelling Tool for the Integration of Biomechanical and Metabolic Aspects during Movement. IUTAM Symposium on Human Movement Analysis and Simulation, Leuven, 13-15 September 2010. http://www.mech.kuleuven.be/iutam2010/IUTAM proceedings/Abstract posters.html

[44] Constable, J.K., Barclay, C.J. and Gibbs, C.L. (1997) Energetics of Lengthening in Mouse and Toad Skeletal Muscles. Journal of Physiology, 505, 205-215. http://dx.doi.org/10.1111/j.1469-7793.1997.205bc.x

[45] Bisciotti, G.N. and Eirale, C. (2013) Etiology, Biology and Treatment of Muscular Lesions. In: Bisciotti, N. and Eirale, C., Eds., Muscle Injuries in Sport Medicine. http://www.intechopen.com/books/muscle-injuries-in-sport-medicine/etiology-biology-and-treatment-of-muscular-lesi $\underline{\text { ons }}$ 
Scientific Research Publishing (SCIRP) is one of the largest Open Access journal publishers. It is currently publishing more than 200 open access, online, peer-reviewed journals covering a wide range of academic disciplines. SCIRP serves the worldwide academic communities and contributes to the progress and application of science with its publication.

Other selected journals from SCIRP are listed as below. Submit your manuscript to us via either submit@scirp.org or Online Submission Portal.
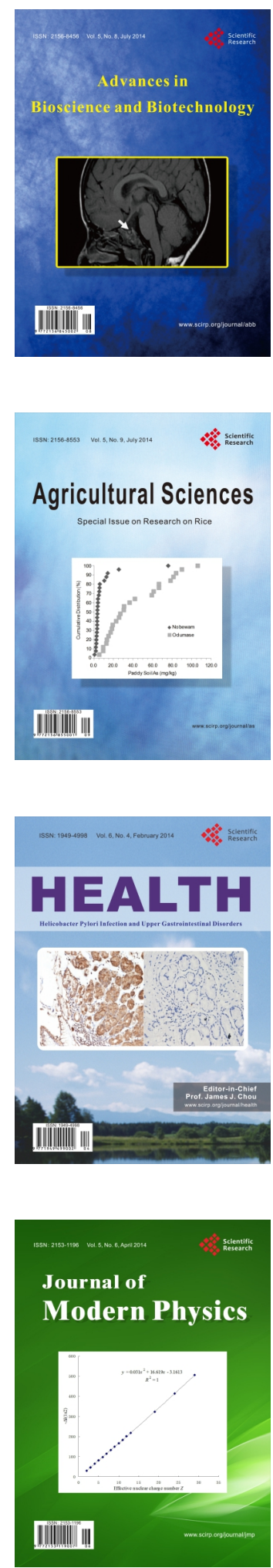
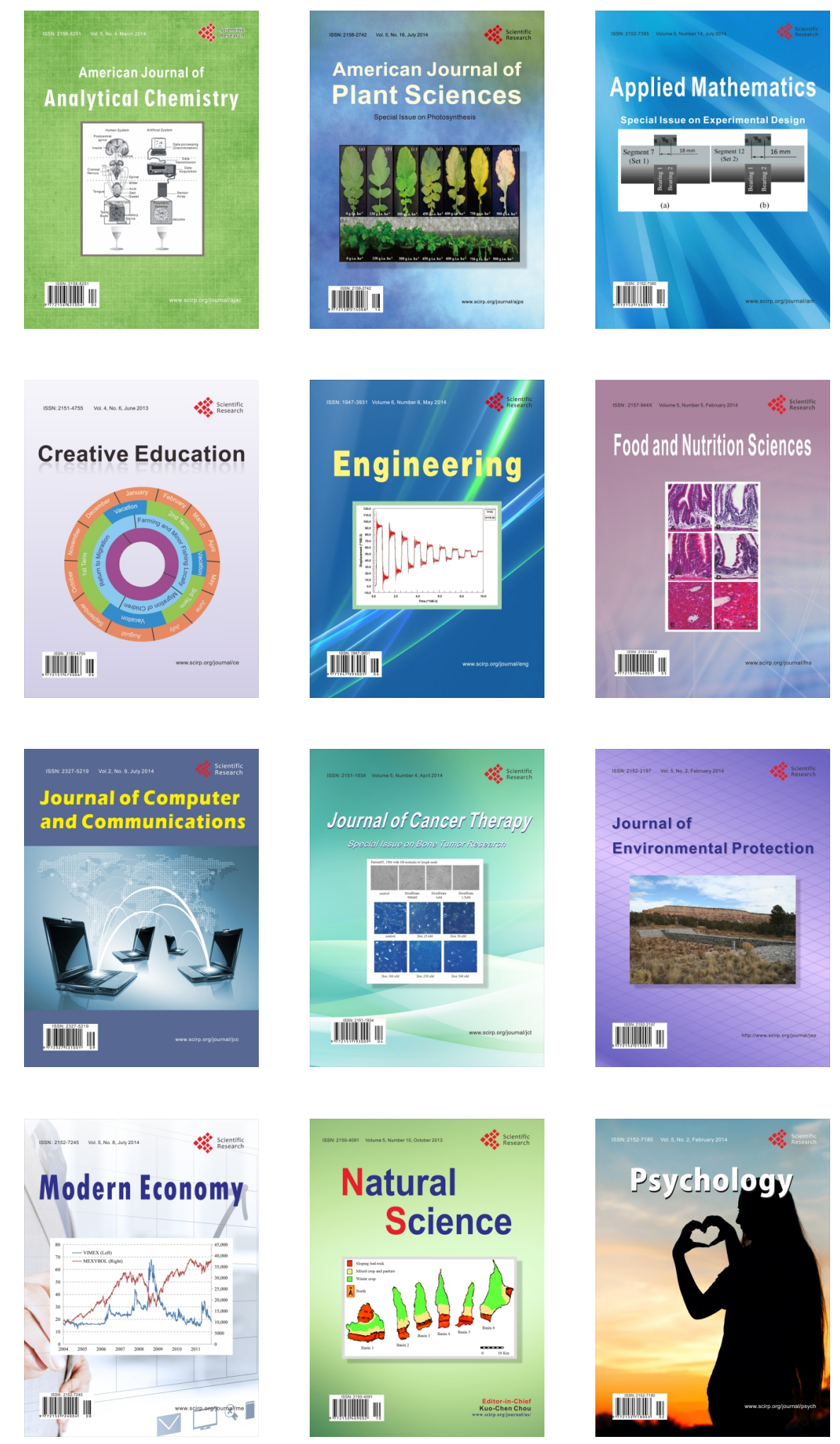